\title{
Seasonal dynamics of insect pests of sugar beet under sub-tropical conditions
}

\section{SMRITI SHARMA, RUBALJOT KOONER, SIKANDER SINGH SANDHU, RAMESHARORA, TARUNDEEP KAUR*and SIMERJEET KAUR*}

\author{
Department of Entomology, *Department of Agronomy, \\ Punjab Agricultural University, Ludhiana 141004 \\ Email-smritisharma80@pau.edu
}

\begin{abstract}
The present study was conducted for three years (2012-13 to 2014-15) on sugar beet crop at PAU, Ludhiana to establish the relationship between weather parameters and insect pests infesting sugar beet crop. The observations on the incidence of insect pests recorded at weekly intervals were analyzed to correlate the effects of the abiotic factors on population of insect pests. Aphid, Myzus persicae Sulzer population showed negative correlation with maximum and minimum temperature and positive correlation with relative humidity. Spodoptera litura Fabricius and Helicoverpa armigera (Hubner) showed positive correlation with maximum and minimum temperature and negative with relative humidity. Regression analysis was also worked out between population of these insect pests infesting sugar beet.
\end{abstract}

Key words: Insect pests, population dynamics, sugar beet, climatic factors

Weather affects the distribution and abundance of any species at both individual and population level affecting the insect migration, outbreaks through affecting physiology, behavior and population densities (Parmesan, 2007). Moreover, response of organisms to climatic variation is species specific occurring at different rates in each species thus, resulting in an altered community structure (Sharma et al., 2014). It has also been reported that many biological processes undergo sudden shifts at particular threshold values of specific months might be more important in regulating insect population as compared to annual mean temperature (Guldberg, 2001). Hence, understanding the complex interaction between insect pests and weather parameters would help in developing efficient and timely pest control strategies.

Sugar beet, Beta vulgaris Linnaeus is an important agricultural asset being a pure source of sucrose and its cultivation is economical than sugarcane with 30 per cent more sugar harvested in a short duration thus, offering an excellent opportunity to increase sugar productivity. Sugar beet is primarily a crop of the temperate region and contributes about 22-28 per cent of the world sugar production (Solomon, 2013), but advances in genetics and agrotechnology have extended its scope to the sub-tropics where it can be cultivated during winter season.

In India, defoliating insects viz .beet armyworm (Spodoptera litura Fabricius), hairy caterpillar (Diacrisia obliqua Walker), semilooper(Plusia orichalcea Fabricius), cutworm (Agrotis ypsilon Rott.) cause appreciable damage to sugar beet at different growth stages in India (Patil et al., 2007). Manoharan et al. (2010) reported S. litura as the predominant pest on sugar beet The gram pod borer, Helicoverpa armigera (Hubner) is a polyphagous pest of economic importance on many agricultural and horticultural crops including 180 cultivated and wild plant species (Venette et al., 2003). Sugar beet could be integrated in present cultivation schedule to obtain higher sugar productivity and for this goal, it is imperative to study the population fluctuations of insect pests on sugar beet in relation to weather parameters that determine the activity and abundance.

\section{MATERIALS AND METHODS}

The studies were conducted on sugar beet crop sown during October for three consecutive years 2012-13 to 2014-15 at Agronomy Research Farm, Punjab Agricultural University, Ludhiana. The crop was raised without any insecticidal application so as to estimate the natural population of insect pests infesting this crop. The data pertaining to insect pests was recorded at weekly intervals initiating on one month old crop till harvest, in accordance with standard meteorological week (SMW). For calculating the weekly mean incidence, the observations on the incidence of insect pests were taken from selected plots from an area 


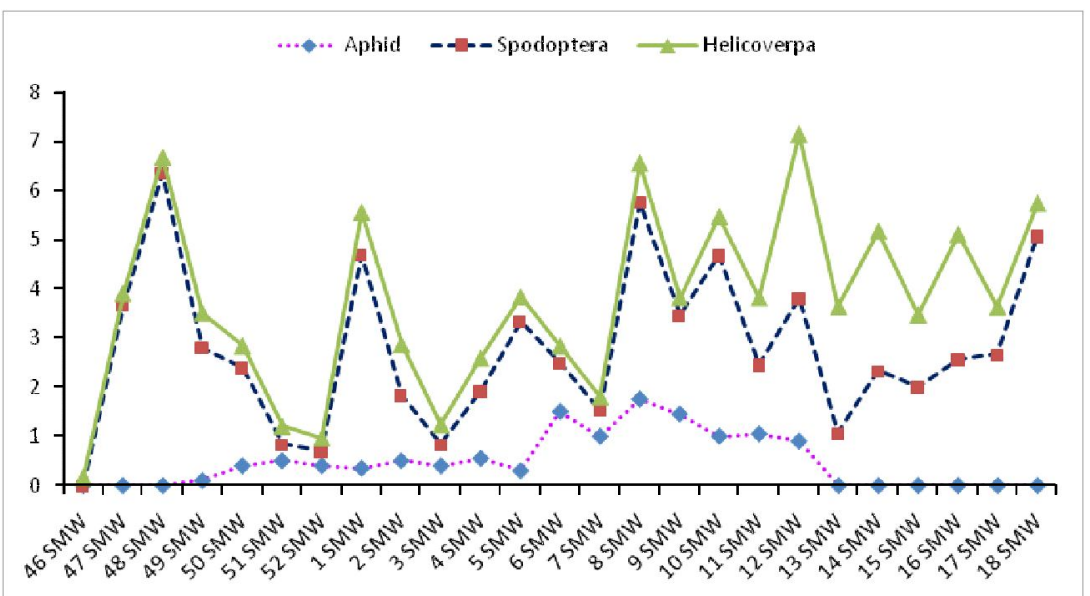

Fig 1: Seasonal abundance of aphids (nos. per leaf), S. litura and H. armigera (nos. of larvae per plant) on sugar beet

Table 1: Correlation coefficient of insect pests on sugarbeet with weather parameters

\begin{tabular}{llll}
\hline Weather Parameter & \multicolumn{2}{l}{ Correlation coefficient $(\mathrm{r})$} \\
& M. persicae & S. litura & H. armigera \\
\hline Max temp $\left({ }^{\circ} \mathrm{C}\right)$ & $-0.398^{*}$ & $0.609^{* *}$ & $0.478^{* *}$ \\
Min temp $\left({ }^{\circ} \mathrm{C}\right)$ & -0.284 & $0.718^{* *}$ & $0.599^{* *}$ \\
RH $(\%)$ & $0.586^{* *}$ & $-0.511^{* *}$ & -0.325 \\
Rainfall $(\mathrm{mm})$ & $0.482^{* *}$ & 0.042 & -0.036 \\
\hline
\end{tabular}

* Significant at $\mathrm{p}=0.05$ level

** Significant at $\mathrm{p}=0.01$ level

of 500 sq. $\mathrm{m}$ with five replications. The number of larvae of $S$. litura and $H$. armigera was taken from ten randomly selected plants starting from $49^{\text {th }}$ SMW of each year. The aphid counts were taken from upper and middle three leaves of ten randomly selected plants for calculation of weekly means starting from the $49^{\text {th }}$ SMW. The data on maximum and minimum temperature, rainfall and relative humidity $(\mathrm{RH})$ during 2012-13 to 2014-15 was obtained from School of Climate Change and Agricultural Meteorology, PAU, Ludhiana during the months under study. Correlation and Regression equations were calculated to estimate the effects of these abiotic factors on population counts of insect pests.

\section{RESULTS AND DISCUSSION}

\section{Population dynamics of insect pests}

Three years (2012-13 to 2014-15) mean data of aphids (M.persicae), S.litura and H. armigera is presented in Fig. 1. The incidence of insect pests on sugar beet was observed in $46^{\text {th }}$ SMW and continued till the $18^{\text {th }}$ SMW of next year in all the years under present study. Aphids were found to appear in $49^{\text {th }}$ SMW and attained peak values (>1.00) during 6-9 $9^{\text {th }}$ SMW. Thereafter, it decreased and disappeared after $13^{\text {th }}$ SMW. The larvae population of S. litura and $H$. agrmigera were found to vary during the season, however, both the insect/pests showed similar variation pattern. The larvae count of $H$. armigera were slightly higher than that of S.litura.(Fig. 1.)

\section{Correlation with weather parameters}

Correlation was worked out between population of these insect pests infesting sugar beet and meteorological parameters to study the effect of abiotic factors on pest population. It was observed that $M$. persicae population showed negative correlation with maximum and minimum temperatures and highly significant positive correlations with relative humidity and rainfall. H. armigera showed highly significant positive correlations with maximum and minimum temperatures and negative but non-significant correlations with relative humidity and rainfall. S. litura showed significant positive correlations with maximum and minimum temperatures and significant negative correlation with relative humidity.

On the basis of highest correlations obtained with different weather parameters, simple regression equations were developed for each pest. The best regression equation for $M$. persicae is $\mathrm{y}=14.08 \mathrm{x}+63.12\left(\mathrm{R}^{2}=0.343\right)$ which explains $34.3 \%$ variation in its population. Maximum temperature was found to explain maximum variation in 
S.litura $(\mathrm{y}=-3.245 \mathrm{x}+77.37)$ with $\mathrm{R}^{2}=0.515$ and for $H$. armigera the model equation $\mathrm{y}=3.084 \mathrm{x}+7.996\left(\mathrm{R}^{2}=0.359\right)$ explains 35.9 per cent variation. These models can be used for predicting the insect/pest population on sugar best at Ludhiana.

Saxena et al., (2012) observed that population build up of Lipaphis erysimi in mustard was negatively correlated with maximum and minimum temperature. In yet another study conducted by Sharma et al., (2013), it was observed that aphid population on tomato was positively but nonsignificantly correlated with the maximum, minimum temperature and negative non-significantly correlated with relative humidity (maximum and minimum) and rainfall. Studies by Thakur and Rawat (2014) reported a positive correlation between the insect pest trap catches of Helicoverpa spp. and Spodoptera spp. and abiotic factors viz. maximum temperature and minimum temperature, relative humidity and rainfall. The results of present study are also in coherence with the findings of Singh et al. (2011) who reported that rainfall and relative humidity were negatively correlated with the pest activity, whereas the maximum and minimum temperature, were positively correlated with relative humidity.

\section{CONCLUSION}

From the present studies, it could also be concluded that aphid, M. persicae population on sugar beet showed negative correlation with maximum and minimum temperature and positive correlation with relative humidity. S. litura and H. armigera showed positive correlation with maximum and minimum temperatures and negative correlation with relative humidity.

\section{REFERENCES}

Hoegh-Guldberg, O. (2001). Sizing the Impact: Coral reef ecosystems as early casualties of climate change. In: "Fingerprints of Climate Change - Adapted Behavior and Shifting Species Ranges" (Eds. G. R. Walther, C. A. Burga and P. J. Edwards). (Kluwer Academic Publ., USA).

Manoharan, T., Pathma, J. and Preetha, G. (2010).Seasonal incidence of sugar beet pests and natural enemies.
Indian J. Ent., 72(1):36-41.

Parmesan, C. (2007). Influence of species, latitudes and methodologies on estimates of phonological response to global warming. Global Change Bio., 13:1860-1872.

Patil,A. S., Salunkhe,A. N., Pawar,B.H., Ghodke, P.V., Shivankar, S. B., Zende, N. B., Shewate, S. R. and Patil, D.J. (2007). Sugarbeet cultivation in tropical India-Anew experience. In:Proceedings of $68^{\text {th }}$ Annual Convocation, STAI, New Delhi, 22-24 August, 2007:85-111.

Saxena, S., Murty, N.S. and Singh, C.P. (2012).Effect of weather parameters on population dynamics of mustard aphid (Liaphis erysimiKalt)in Tarai region of Uttarakhand. $J$. Agrometeorol., 14:176-177.

Sharma, D., Maqbool, A., Ahmad, H., Srivastava, K., Kumar, M., Vir, V. and Singh, J. (2013). Effect of meteorological factors on the population dynamics of insect pests of tomato.Veg. Sci., 40(1): 90-92.

Sharma, S., Arora, R. and Singh, B. (2014).Impact of climate change on agriculturally important insects. $J$. Insect Sci., 27:159-188.

Singh, K., Raju, S.V.S. and Singh, D.K. (2011). Population succession of tomato fruit borer (Helicoverpa armigera) on tomato (Lycopersicon esculentum Mill.) agroecosystem in eastern region of U. P. Veg. Sci., 38(2):152155.

Solomon, S. (2013). Sugar beet as an energy crop. In:Souvenir IISR-Industry Interface on Research and Development Initiatives for Sugar beet in India, (Eds. S. Kumar, P.K. Singh, M. Swapna and A.D. Pathak) May 28-29, 2013, (Sugar beet Breeding Outpost of IISR, IVRI Campus, Mukteswar, Nainital).

Thakur, M. and Rawat, S. (2014).Effect of abiotic factors on population dynamics of insect pests and natural enemies in potato crop. J. Agrometeorol., 16:187-191.

Venette, R.C., Davis, E.E., Zaspel, J., Heisler, H. and Larson, M. (2003).Mini risk assessment old World bollworm, Helicoverpa armigeraHübner (Lepidoptera: Noctuidae). Cooperative Agricultural Pest Survey, Animal and Plant Health Inspection Service, US Department of Agriculture. 